\title{
Geopolítica do espaço cibernético e o poder: o exercicio da soberania por meio do controle
}

\author{
Geopolitics of cyber space and power: \\ the exercise of sovereignty by control
}

Rev. Bras. Est. Def. v. 5, nº 1, jan./jun. 2018, p. 141-165

DOI: 10.26792/RBED.v5n1.2018.75081

ISSN 2358-3932

\section{LUCAS SOARES PORTELA}

\section{INTRODUÇÃO}

Os espaços geográficos tradicionais - terrestre, marítimo e aéreo - sempre existiram, mas a territorialização, ou seja, o uso pelo homem ocorreu no decorrer da história (Portela 2015). Conforme Edward Burns (1948), o primeiro ápice das artes e ciências humanas somente foi alcançado próximo do ano 3000 a.C. Ainda na chamada Idade da Pedra, quando a humanidade vivia em nomadismo, não havia um trabalho territorial em nível de sociedade, sendo o espaço terrestre puro.

Se, no espaço terrestre, a territorialização demorou a acontecer, os demais espaços somente vieram a ser explorados no último milênio. Inclusive o geopolítico clássico, Rudolf Kjellén, que nasceu no século XIX, tratava apenas da luta do Estado por mais espaço no ambiente continental. Para ele, o espaço marítimo ainda não era uma preocupação para o Estado. O uso de cada um dos espaços geográficos tradicionais com vistas à sobrevivência humana, requereu do homem a sua organização e sua proteção, por meio de um agir estratégico.

Também para responder à demanda humana, a Internet surge no meio acadêmico, dentro do imaginário do homem, sendo utilizado desde sua origem. A nomenclatura "espaço cibernético" somente surgiu no ano de 1948, dentro da publicação do romance "Neuromancer" do escritor William Gibson. Esse autor utilizou esse termo para explicar o conjunto de tecnologia que, juntamente com a Internet, modificava a estrutura social de sua ficção. $\mathrm{O}$ que se dizia na ficção se revelou na sociedade. A relevância que

Lucas Soares Portela - Mestre em Ciências Militares pela Escola de comando e Estado-Maior do Exército exerce docência em Relações Internacionais no Centro Universitário de Brasília (UniCEUB). 
esse espaço tomou na vida da sociedade e do homem já é objeto de desavenças entre homens e litígios entre Estados.

Na configuração contemporânea, Richard Clarke (2010) define o espaço cibernético como o conjunto de tecnologias atreladas à rede de computadores do mundo, como todas as coisas que são controladas por esses equipamentos. Por isso, utilizar o termo espaço cibernético e Internet como sinônimos resulta em engano, pois a Internet representa parcelas do espaço cibernético que estão interconectadas. Para Clarke (2010), o conceito de espaço cibernético é mais amplo que a própria Internet.

Pode-se inferir que, dentro desse conceito, a informação que circula são recursos do território (Portela 2015). Da mesma forma, o usuário não constitui território, sendo apenas seu operador, constituindo a camada chamada de peopleware por Daniel Ventre (2012). Sendo assim, a ação do Estado também possível e considerada dentro desse ambiente, como este artigo tratou em seu corpo.

Atualmente, muito se tem falado sobre a equiparação do espaço cibernético a um espaço geográfico, delimitações de fronteira, soberania de Estado, controle governamental e disputa de poderes. Em meio a tantas colocações, a resposta do que é o espaço cibernético pode ser apontada pela Geografia, mais especificadamente pela Geopolítica, conforme Gonzales e Portela (2017). A importância do espaço cibernético para o Estado tem uma relação direta com seu poder e soberania, conceitos que estão interligados ao espaço, universos estes que são estudados pela Geopolítica.

Apesar dessa matéria ter uma ligação estrita com esses conceitos clássicos - poder e espaço - tem evoluído juntamente com a dinâmica mundial para abarcar as mudanças políticas. Rudolf Kjellén não tratava do ambiente aéreo e marítimo não por um pecado de sua obra, mas por uma limitação tecnológica, e isso não impediu a geopolítica de tratar desses ambientes atualmente. Assim, esse artigo pretendeu responder ao problema: a dinâmica do poder do século XXI gera uma territorialização do espaço cibernético como um espaço geográfico? A hipótese que norteou o artigo afirma que a projeção de poder, visando o controle, dentro do espaço cibernético, seja por Estados ou outros atores, desenha uma relação que se enquadra dentro da chamada Nova Geopolítica.

A pretensão de se discutir o espaço cibernético como possível objeto da geopolítica a partir da análise da aplicação contemporânea dos conceitos de espaço e poder se manteve a partir da premissa de que, atualmente, a busca por mais espaço não é o principal fator de disputas, mas as informações. Não se afirma aqui que o desejo por posse das fontes de recursos não sejam objetos de disputas entre Estados. Pelo contrário, a busca por elas evolui a um grau de sensibilidade que uma dada informação pode garantir novos 
recursos e, consequentemente, poder. O nível de detalhamento que se pode conseguir no espaço cibernético sobre uma região, a dinâmica de um local ou a situação de um país é tão grande ou maior do que a de um agente de campo, com o benefício do anonimato.

Sendo o espaço cibernético um tabuleiro de disputa de poderes, que constantemente tem crescido e impactado na geopolítica do mundo, seu domínio é uma ferramenta desejada. Salvaguardados os questionamentos, esse espaço pode impactar no equilíbrio de poder mundial, pois sua utilização para projetar poder requer baixos investimentos, permitindo um ataque a um Estado promovido por apenas um indivíduo, o que Joseph Nye Jr. chama de difusão de poder. Essas são apenas algumas das questões que preocupam a geopolítica. A análise desse espaço pela geopolítica, entretanto, não pode ser realizada sem o devido enquadramento nas premissas e conceitos anteriormente mencionados.

Para responder a essa necessidade e ao objetivo proposto, o artigo foi estruturado em quatro tópicos temáticos. Primeiramente, observou-se a evolução da Geopolítica, com foco nos principais fatores que eram considerados e como que eles atualmente são tratados dentro da própria matéria. Posteriormente, discutiu-se as categorias constitutivas que tornam uma área e um ambiente em um espaço geográfico. Após, aborda-se o peso do poder dentro da geopolítica contemporânea. Por último, abordou-se a geopolítica do espaço cibernético como um fator de controle necessário para a garantia do poder.

Por ser um texto de discussão teórica, não se pretendeu aqui abordar profundamente questões empíricas. Isso não significa que não as consideramos - apenas as utilizamos como exemplificações das colocações e apontamentos realizados. Dessa forma, o artigo tomou o formato de uma pesquisa bibliográfica, com análise especialmente de fontes secundárias.

\section{EVOLUÇÃO DA GEOPOLÍTICA E FATORES RELACIONAIS}

Analisar a geopolítica no espaço cibernético requer primeiramente uma revisão da evolução do pensamento geopolítico e uma revisita às principais teorias. Mesmo que breve, a revisão bibliográfica permite compreender as mudanças ocorridas e, principalmente, as discordâncias surgidas ao longo da história, em especial na chamada nova geopolítica. Focar nas mudanças permitiu compreender os fatores relacionais responsáveis pela evolução da geopolítica,

Por fatores relacionais, entende-se referências que causaram a mudança da geopolítica no decorrer da história, como, por exemplo, o território. Quando se analisam as teorias clássicas e se comparam com as novas teo- 
rias, nota-se que o espaço perde um pouco da sua importância como fator relacional, dando maior relevância ao poder. Assim um olhar mais específico da evolução dos fatores relacionais permite compreender como uma geopolítica do espaço cibernético poderia ser referenciada.

O termo "geopolítica" surge com o alemão Rudolf Kjellén, em 1905, mas sua consolidação se deu no decorrer do século XX. Antes de cunhado o próprio termo, trabalhos anteriores - nas áreas de Geografia, Teoria Política e Estudos Estratégicos - já discutiam dilemas da geopolítica, como os teóricos Mahan e Mackinder, em 1890 e 1904, respectivamente. A partir de um entendimento filosófico, a geopolítica pode ser definida como o "conjunto de conhecimentos não ingênuos, que apresentam graus diversos de sistematização e de credibilidade, e que se propõe a explicar, elucidar, interpretar ou unificar um dado domínio de fenômenos ou de acontecimentos que se oferecem à atividade prática" (Bonfim 2005, 55).

De Mahan (1890) a Spykman (1942), os estudos geopolíticos tentavam delimitar a melhor região do globo para que um Estado tivesse uma posição de domínio sobre os demais ou o tipo de dominação que lhe daria maior poder. Mahan acreditava que o desenvolvimento de um Estado deveria se dar pelo mar e por isso dominar a guerra naval (Violante 2015). De forma semelhante, Mackinder (1904) acreditava que o Estado detentor da região próximo à Crimeia poderia dominar o mundo, pois ali encontraria diferentes acessos ao mar, ou seja, dominaria o continente e os oceanos (Villa 2000). Também tentando determinar o espaço necessário para o desenvolvimento do Estado, Haushofer (1930) cria o conceito de Espaço Vital, em que o Estado necessita de uma área proporcional à sua população para obter recursos necessários para se tornar desenvolvido (Losano 2008).

Por outro lado, alguns geopolíticos começaram a tentar sobrepor as teorias existentes. Por exemplo, Douhet (1921) afirma que através do domínio aéreo era possível irromper com os domínios marítimo e terrestre, inclusive o domínio do Espaço Vital. Spykman (1942) também desenvolveu uma teoria para conter o possível controle do Hartland, em que um Estado deveria dominar os acessos àquela região, as "fímbrias" ou Rimland.

Embora as teorias clássicas tivessem referências no espaço, havia um grupo menor de geopolíticos que já desenvolvia teorias com maior referência ao poder. Dentre eles, vale citar Seversky (1942), que divide o domínio aéreo em duas regiões, uma dominada pelos EUA e outra pela URSS. Por sua vez, em 1975, Cline tenta criar uma fórmula para definição do poder de um Estado, ranqueando o mundo. Cabe lembrar, ainda, de Taynbee (1934), que visualizava a geopolítica como uma ferramenta política nas mãos das elites.

O fator relacional "poder" ganhou maior relevância nas chamadas novas teorias da geopolítica, quando os acadêmicos começaram a tentar 
compreender o mundo pós-Guerra Fria. Em 1991, Jacques de Brochard elabora a "Teoria dos Blocos" também conhecida como "Teoria da Zonas Monetárias". Essa segunda denominação torna a teoria de Brochard auto descritiva, pois ele divide o globo em zonas de liderança monetária, em que o país mais forte lidera e sua moeda vigora em toda a região. Assim, o mundo é dividido em quatro blocos, a saber: Federação das Américas, Confederação Eurafricana, União das Repúblicas Soberanas e Liga Asiática.

No mesmo ano, Jean Rufin publica a "Teoria dos Limes", que defendeu uma reorientação do enfretamento clássico Leste-Oeste para uma dinâmica Norte-Sul. Conforme seu trabalho, com o fim da Guerra Fria, os Estados ricos não precisavam mais dos Estados pobres do Sul, podendo priorizar seus próprios problemas e seu desenvolvimento. Os Estados do Norte se fecham numa fortaleza para instalações crescentes de zonas de instabilidade que garantam uma "nova ordem mundial" baseada na multipolaridade. As zonas seriam linhas de confinamentos onde assegurariam que os "bárbaros do Sul” fossem controlados; tais zonas foram conceituadas por Rufin como "dobradiças".

No ano seguinte, 1992, o francês Pierre Lellouche publica seu texto sobre o que chamou de "Teoria da Incerteza” em que questionou a colocação de Jean Rufin. Para ele, a "nova ordem mundial” não seria pautada em uma disputa Norte e Sul, mas na ausência de ordem. Acreditava que os Estados Unidos não conseguiriam provocar uma ordem mundial, e que a desordem instaurada seria causada por instabilidades e revoluções na região da antiga União Soviética, explosões demográficas na África, distúrbios raciais e étnicos nos EUA e ameaças nucleares de países do norte da África contra a Europa, rearmamento do Japão e abertura chinesa ao Japão e resto do ocidente.

Também em 1992, o chamado Clube de Roma - grupo de pessoas influentes no cenário internacional que se reúnem para debater temas relativos ao mundo, e que iniciou suas atividades em 1961 - contribui para a geopolítica com a criação da "Teoria da Tríade", que dividiu o mundo em três centros de poder, a saber: Bloco Americano, Bloco Europeu e Bloco Asiático. Semelhante à Teoria dos Limes de Rufin, a Teoria da Tríade defende que cada um desses blocos teria dinâmicas e lideranças suficientes para que o mundo esteja em uma situação de harmonia.

No ano seguinte, com finalização em 1996, Samuel Huntington desenvolve a "Teoria do Choque de Civilizações", que defendeu o fim dos conflitos tradicionais, aqueles causados por questões militares clássicas e a ascensão de conflitos por razões étnicas, religiosas e raciais. Diante de referências desses temas, Huntington divide o mundo em nove regiões, quais sejam: mundo ocidental, islâmico, confucionista, budista, ortodoxo, 
hindu, japonês, africano e latino. A principal premissa dessa teoria é que as relações sociais se pautam pela referência maior de sua existência, a civilização pertencente.

O trabalho de Huntington não agradou a muitos acadêmicos, principalmente porque questões de cunho étnico-religioso causam muita sensibilidade. Além disso, a divisão de certas regiões do mundo causou incômodo, como por exemplo, a América Latina, que não foi considerada como ocidente e foi apontada como instável, o que gerou teorias que questionavam esse modelo. Por exemplo, o brasileiro Roberto Mafra publicou em 1996 a "Teoria do Quaterno", que dividia o mundo em Bloco Norte-Americano, Bloco Sul-Americano, Bloco Europeu e Bloco Asiático, ou seja, contesta a divisão de Huntington.

Outro geopolítico brasileiro de renome é Terezinha de Castro (1999), que estudou as qualidades necessárias para que um Estado seja poderoso, a saber:

1. Superfície territorial maior que 5 milhões de $\mathrm{km}^{2}$;

2. Continentalidade territorial;

3. Acesso direto e amplo ao oceano;

4. Recursos naturais estratégicos essenciais;

5. População maior que 100 milhões de habitantes;

6. Densidade demográfica maior que $10 \mathrm{hab} . / \mathrm{km}^{2}$;

7. Homogeneidade racial.

Diante dessas categorias de Terezinha de Castro (1999), é possível questionar, por exemplo, o porquê de o Brasil não ser uma superpotência, haja vista que satisfaz todos os critérios acima mencionados. Embora algumas características tenham ligação com espaço, como as três primeiras, as três últimas são mais ligadas à capacidade e potencial, binômio com maior relação ao poder. Sobre isso, pode-se inferir ainda que as teorias clássicas estavam preocupadas em fornecer referências territoriais que dariam poder ao Estado, enquanto as novas teorias tentam explicar o mundo diante da incerteza gerada pelo fim da Guerra Fria.

Igualmente, nas novas teorias, uma geopolítica para o espaço cibernético não vislumbra evidenciar a importância desse ambiente para os Estados. É patente que o domínio de informações e dados que trafegam no espaço cibernético pode gerar poder, especialmente Poder Inteligente. ${ }^{1}$ Entretanto, a incerteza de como lidar com esse espaço e como se posicionar preocupa os Estados, o que justifica uma geopolítica do espaço cibernético que norteie a ação dos atores estatais - assim como nas demais teorias atuais, preocupação das teorias clássicas. 


\section{CATEGORIAS CONSTITUTIVAS DO ESPAÇO GEOGRÁFICO}

Na aplicação popular, os conceitos de espaço e território são, por vezes, utilizados sinonimamente. Apesar da aproximação de seus significados, esses dois conceitos apresentam distinção quando tratados dentro da geopolítica. A principal diferença está na aplicação e referência de cada um deles.

Termos clássicos tendem a ter significados conforme a área aplicada. $\mathrm{O}$ território pode ser definido dentro de diversas vertentes, como por exemplo, a biologia que o define como a área de vivência de uma espécie ou a psicologia que o vincula com a defesa de um espaço por uma pessoa.

Apesar da variação, percebe-se que todas as definições de um território apresentam a essência da ligação com um ser, seja humano, animal ou Estado. Tal afirmação também está presente dentro da definição de território pela Geopolítica. Conforme o alemão Friedrich Ratzel (2011), o território é o espaço sobre o qual a soberania de um Estado é exercida:

2. O Estado é uma fração de humanidade e uma fração de solo. $\mathrm{O}$ homem não é concebível sem o solo terrestre, ainda mais sem a maior obra do homem sobre terra: o Estado. Assim como os termos cidade e estrada expressam, respectivamente, uma fração de humanidade e uma obra humana; quando se fala de Estado, designa-se uma fração de superfície terrestre. O Estado é obrigado a viver do solo. Ele possui invariavelmente apenas as vantagens oferecidas por um solo que lhe é assegurado. É o que exprime a ciência política quando diz que o território pertence à essência do Estado. Ela designa a soberania como jus territoriale e estabelece a regra de que as mudanças territoriais podem fazer-se apenas por leis (Ratzel 2011,51).

Assim, o território se encontra dentro do conceito de espaço e está vinculado com a atuação do homem dentro de determinada região. Da mesma forma Raffestin (1993) define território como espaço trabalhado pelos homens. Ainda conforme esse autor, o espaço seria algo cru e preexistente ao território, pois ainda não sofreu com a ação do homem naquele ambiente.

O que condiz com a definição de territorialização, que é o processo em que o homem age dentro de um território - no caso do Estado, a aplicação da soberania. Em uma definição mais ampla, Milton Santos (1986) define o território como um dos três elementos constitutivo de um Estado-Nação, juntamente com a população e a soberania. Logo, o espaço existe sem o território, mas este coexiste com aquele em uma relação estrita dentro da aplicação da soberania do Estado.

Dito isso, quais são os elementos constitutivos do espaço? Primeiramente, deve-se ter atenção à variação do conceito nos diversos ramos do conhe- 
cimento, assim como visto no caso do termo território. Entretanto, sua variação geralmente vem acompanhada da indicação de aplicação, como, por exemplo, espaço social, espaço político, espaço educacional. No caso da geopolítica, o espaço que este artigo abordou foi o espaço geográfico.

Para definir esse conceito também recorremos a Milton Santos (1986) e a Claude Raffestin (1993). No caso deste, a definição já foi mencionada anteriormente como algo dado e preexistente a qualquer ação do homem, como um quadro branco a ser colorido. No caso de Milton Santos (1986) o espaço geográfico é definido como:

O espaço deve ser considerado como um conjunto de relações realizadas através de funções e de formas que se apresentam como testemunho de uma história escrita por processos do passado e do presente. Isto é, o espaço se define como um conjunto de formas representativas de relações sociais do passado e do presente e por uma estrutura representada por relações sociais que estão acontecendo diante dos nossos olhos, e que se manifestam através de processos e funções. O espaço é, então, um verdadeiro campo de forças cuja aceleração é desigual. Daí porque a evolução espacial não se faz de forma idêntica em todos os lugares.

Em sua definição, podemos compreender o "espaço" como o campo de atuação das forças sociais. Vale notar que esse campo é relativo ao tempo e à estrutura vigente. Assim, o espaço em que o Brasil se encontra hoje é distinto daquele da Velha República. Igualmente, o espaço em que o Brasil se encontra é diferente daquele em que a Argentina se encontra, pois contém estruturas e relações sociais distintas. De forma mais evidente, o espaço em que as relações sociais acontecem no ocidente é bastante diferente daquele de certos países asiáticos.

Dessa forma, seria errôneo tratar e aplicar de forma pura as teorias clássicas da geopolítica ao espaço cibernético, principalmente porque este é um fruto da contemporaneidade. Tão lógica é essa premissa sobre o "espaço" que não se pode tratar o espaço cibernético atual como aquele espaço cibernético da ArpaNET. ${ }^{2}$ Logo, a aplicação da geopolítica requere constantes avaliações e adequações ao momento histórico corrente.

A principal diferença entre as definições de Santos (1986) e Raffestin (1993) está na concepção do Estado sem o poder e ação do homem. Para Raffestin (1993) é aceitável a existência do espaço sem sua territorialização, enquanto para Santos (1986) sua existência surge apenas em caso de interações sociais. Quando aplicados ao espaço cibernético, a definição de Santos (1986) melhor atende, pois caso não haja relações sociais na camada peopleware, ou seja, a atuação dos operadores e usuários, esse 
espaço geográfico deixa de existir, já que sua existência não pode ter fim em si mesma.

Dessa forma, poderíamos considerar o espaço cibernético como espaço e território, com estes conceitos tratados quase como sinônimos. Embora haja constantes processos de reterritorialização e de territorialização ${ }^{3}$ no espaço cibernético (Ferreira Neto 2014), o espaço cibernético nunca deixaria de ser território, pois os dois apresentam movimentos constantes e uma relação cíclica definitiva. Assim, a definição de neo-espaço geográfico ao espaço cibernético depende do enquadramento das duas principais categorias de análise da Geopolítica - poder e espaço.

Apesar de termos afirmado a necessidade de uma releitura desses conceitos para uma correta aplicação nos espaços geográficos atuais, o que se percebe na bibliografia da Geopolítica é a permanência da premissa inicial que deu origem a essa disciplina. Podemos afirmar que desde sua existência a Geopolítica se apoia na necessidade do Estado de se obter espaço para garantia de sua sobrevivência. Entretanto, não é uma busca por espaço como fim em si mesmo, mas da busca por disponibilidade de recursos que garantam poder.

O Estado não buscaria apenas a maior porção de terra, mas o domínio de uma reunião que tivesse maiores recursos ou acesso a recursos. $\mathrm{O}$ espaço que era considerado estratégico para a sobrevivência de um Estado foi definido por Friedrich Ratzel como "espaço vital". De acordo com o professor Wanderley Costa (1992), a relação entre crescimento de um Estado e o espaço para sua sobrevivência, base do conceito de "espaço vital", tem respaldo na necessidade da população nacional.

Embora na atualidade ainda existam conflitos por terras e tensões fronteiriças, estas abrangem, na maioria dos casos, questões mais amplas que a própria terra, conforme demonstrado por Samuel Huntington (1997). Além disso, diante da necessidade de atender às demandas da população nacional, os Estados têm buscado soluções no setor tecnológico e no chamado domínio de informações. Essa mudança de postura tem uma relação estrita com a nova ética global, que abarca questões humanas, ambientais e morais (Singer 2004).

Exemplificando, o Brasil aumentou sua produção de grãos nos últimos anos sem aumentar o território destinado ao plantio. Tal conquista se deu em virtude de avanços científicos e tecnológicos no manejo do cultivo, especialmente por meio de pesquisas da Empresa Brasileira de Pesquisa Agropecuária (Embrapa). Essa não é apenas uma realidade brasileira, mas mundial, haja vista que o aumento da área cultivada causa impactos negativos na sustentabilidade de um Estado. 
Logo, a obtenção de poder por meios além da exploração territorial causa maiores preocupações atualmente do que a expansão territorial, ou seja, na atual conjuntura, poder não é estritamente espaço. Ademais, em virtude da evolução geopolítica do mundo, o fator continente tem um peso relativamente menor no conceito de espaço geográfico do que aquele existente no passado. Diante disso, o tratamento do espaço cibernético como um espaço geográfico se justifica diante das relações sociais e de poderes que ocorrem em seu âmbito.

\section{A NOVA GEOPOLÍTICA E A RELAÇÃO COM O PODER}

Como dito no tópico anterior, a geopolítica tem como referência o tempo e as relações sociais de um determinado grupo. Conforme a estrutura social mudou, as análises geopolíticas também mudaram. Uraci Bonfim (2005) explica que o final da Guerra Fria foi um marco no pensamento geopolítico, principalmente por causa do fim do modelo bilateral de poder, separando as novas teorias da Geopolítica das teorias tradicionais:

\section{Quadro 1}

Evolução das principais teorias internacionais da geopolíticas

\begin{tabular}{|l|l|l|c|}
\hline \multicolumn{4}{|c|}{$\begin{array}{l}\text { TEORIAS DA GEOPOLÍ́TICA CLÁSSICA } \\
\text { (Século XX até o final da Guerra Fria) }\end{array}$} \\
\hline Teoria & Autor & Premissa principal & Ano \\
\hline $\begin{array}{l}\text { Teoria do Poder } \\
\text { Marítimo }\end{array}$ & Mahan & $\begin{array}{l}\text { O poder marítimo é elemento vital para o } \\
\text { crescimento, a prosperidade e a segurança } \\
\text { nacionais. }\end{array}$ & 1890 \\
\hline $\begin{array}{l}\text { Teoria do Poder } \\
\text { Terrestre }\end{array}$ & Mackinder & $\begin{array}{l}\text { Quem controla o heartland (coração da terra) } \\
\text { domina o mundo, pois associa o poder terrestre } \\
\text { e marítimo. }\end{array}$ & 1904 \\
\hline $\begin{array}{l}\text { Teoria das Pan- } \\
\text { Regiões }\end{array}$ & Haushofer & $\begin{array}{l}\text { O Estado necessita de um espaço vital } \\
\text { envolvendo uma gama de recursos para reduzir } \\
\text { sua vulnerabilidade. }\end{array}$ & 1930 \\
\hline $\begin{array}{l}\text { Teoria do Desafio } \\
\text { e da Resposta }\end{array}$ & Taynbee & $\begin{array}{l}\text { O destino dos povos está nas mãos de suas } \\
\text { elites dirigentes e aceita a Geopolítica como } \\
\text { conselheira e indicadora de soluções para essas } \\
\text { elites (Geopolítica como ferramenta política). }\end{array}$ & 1934 \\
\hline
\end{tabular}




\begin{tabular}{|c|c|c|c|}
\hline \multirow[t]{2}{*}{$\begin{array}{l}\text { Teoria do Poder } \\
\text { Aéreo }\end{array}$} & Douhet & $\begin{array}{l}\text { A arma aérea, a arma suprema, podia ela só } \\
\text { irromper sobre os inimigos e obter a decisão, } \\
\text { atacando em massa os centros vitais do } \\
\text { adversário }\end{array}$ & 1921 \\
\hline & Seversky & $\begin{array}{l}\text { O mundo é divido em duas áreas de domínio } \\
\text { aéreo, uma dos EUA e outra da URSS. A } \\
\text { sobreposição das áreas resulta em uma "área de } \\
\text { decisão". }\end{array}$ & 1942 \\
\hline $\begin{array}{l}\text { Teoria das } \\
\text { Fímbras }\end{array}$ & Spykman & $\begin{array}{l}\text { A única defesa possível contra o Hartland seria } \\
\text { ocupando as bordas da "Ilha do Mundo", ou } \\
\text { seja, as "fímbrias" (Rimland) }\end{array}$ & 1942 \\
\hline $\begin{array}{l}\text { Teoria do Poder } \\
\text { Perceptível }\end{array}$ & Cline & $\begin{array}{l}\text { Cria o conceito "politectônico", que define como } \\
\text { "estruturação política”, através de uma fórmula } \\
\text { matemática que propõe determinar o potencial } \\
\text { de poder dos Estados. }\end{array}$ & 1975 \\
\hline \multicolumn{4}{|c|}{$\begin{array}{c}\text { NOVAS TEORIAS DA GEOPOLÍTICA } \\
\text { (Após final da Guerra Fria) }\end{array}$} \\
\hline Teoria & Autor & Premissa principal & Ano \\
\hline Teoria dos Blocos & Brochard & $\begin{array}{l}\text { Divide o mundo em quatro blocos, englobando } \\
\text { Estados dos hemisférios norte e sul, cada um } \\
\text { deles liderado preferencialmente por um ou } \\
\text { mais Estados que compõem o grupo dos sete } \\
\text { grandes (G7) }\end{array}$ & 1991 \\
\hline Teoria dos Limes & Rufin & $\begin{array}{l}\text { Com o fim da bipolaridade, os Estados ricos } \\
\text { não mais necessitam ajudar os Estados pobres } \\
\text { do Sul, como parceiros no contexto mundial, } \\
\text { priorizando tratar dos seus próprios problemas } \\
\text { e de seu desenvolvimento (embate Norte-Sul) }\end{array}$ & 1991 \\
\hline $\begin{array}{l}\text { Teoria da } \\
\text { Incerteza }\end{array}$ & Lellouche & $\begin{array}{l}\text { A “nova ordem mundial” não seria uma ordem } \\
\text { Norte-Sul, tampouco uma ordem, mas uma } \\
\text { desordem mundial. }\end{array}$ & 1992 \\
\hline Teoria da Tríade & $\begin{array}{l}\text { Clube de } \\
\text { Roma }\end{array}$ & $\begin{array}{l}\text { O mundo está divido em três centros de poder, } \\
\text { e por isso não há riscos de conflitos. O mundo } \\
\text { se encontra mais "harmônico". }\end{array}$ & $\begin{array}{c}1961- \\
1992\end{array}$ \\
\hline $\begin{array}{l}\text { Teoria do Choque } \\
\text { de Civilizações }\end{array}$ & Huntington & $\begin{array}{l}\text { O mundo é divido conforme a civilização e por } \\
\text { isso os conflitos futuros serão sobre questões } \\
\text { étnicas e religiosas, não mais por motivos } \\
\text { clássicos. }\end{array}$ & $\begin{array}{r}1993- \\
1996\end{array}$ \\
\hline $\begin{array}{l}\text { Teoria do } \\
\text { Quaterno }\end{array}$ & Mafra & $\begin{array}{l}\text { O mundo em quatro blocos: Bloco Norte- } \\
\text { Americano, Bloco Sul-Americano, Bloco } \\
\text { Europeu, Bloco Asiático. }\end{array}$ & 1996 \\
\hline
\end{tabular}

Fonte: Elaboração própria baseada em Bonfim (2005). 
Conforme demonstrado no Quadro 1, a principal mudança na geopolítica foi a relação entre espaço e poder. Na geopolítica clássica isso era dado como real e intransponível, e a evolução do pensamento se deu apenas em relação ao domínio que mais concederia poder ao Estado. Assim tivemos teorias sobre o domínio terrestre, domínio marítimo e domínio aéreo. Ao observar a evolução das principais teorias da geopolítica já listadas, percebe-se que, nas teorias ditas novas, as divisões não estão relacionadas exatamente ao território, mas às dinâmicas de poder existentes no mundo.

Poder é definido por Joseph Nye Jr. (2012) como recursos, e também pode ser definido como resultados comportamentais. Dentro da primeira definição, Nye (2012) afirma que o poder é definido pelos seus recursos que geram resultados pretendidos por meio de estratégias. Na segunda definição, poder é afetar comportamentos, por meio de coerções, recompensas e atrações, visando os resultados pretendidos.

Ainda conforme esse autor, o fim da Guerra Fria provocou uma mudança na configuração de poder no mundo, o que explica as mudanças de referência na geopolítica. A preocupação dos Estados e dos geopolíticos atualmente é essa configuração de poder. Nye Jr. (2012) afirma que existem dois movimentos de poder na geopolítica: transferência e difusão. $\mathrm{O}$ primeiro movimento ocorre quando o principal player do sistema internacional entra em queda e um novo império ascende, enquanto o segundo é caracterizado pela redistribuição de poder para atores menores, inclusive não-estatais.

Nesse contexto as relações internacionais que ocorrem no espaço cibernético recebem destaque. Esse ambiente possibilita a difusão de poder para indivíduos. De acordo com Nye (2012), os custos para se operar no espaço cibernético são baixos para uma pessoa. Isso, associado à possibilidade de anonimato, propicia que um indivíduo ataque diretamente um Estado, o que de fato pode acontecer. Dessa forma, o espaço cibernético é um ambiente em que as fragilidades dos Estados são exponencialmente aumentadas, diante de outros Estado, empresas, ONGs, opinião pública e próprios indivíduos.

Além da maior complexidade que o sistema atual tem em relação aos anteriores, os conceitos aplicados nas esferas do conhecimento são mais abrangentes, em que todas as percepções de mudanças convergem em uma noção de indefinição. Tal problema conceitual sobre a globalização também ocorre com a soberania, ou seja, no exercício do poder por parte dos Estados. Cabe ressaltar que o conceito de soberania, mesmo tendo o mesmo cerne - exercício do poder - apresenta diversidade de significados.

Raymond Aron (1979), ao escrever "Paz e Guerra entre as Nações", aponta para uma diversidade conceitual para a soberania. Encontramos, 
por exemplo, os termos soberania difusa; soberania concentrada; soberania transnacional; e soberania imperial. Entretanto, percebe-se que "no século XXI, lidar com o conceito de soberania é apreender a considerar todas as faces que ela apresenta no contexto da globalização e o momento em que ela converge de uma definição para a outra" (Portela 2015, 34).

No caso do espaço cibernético, a soberania que se deve observar é aquela chamada de responsável (Portela 2015). Isso porque, conforme apontado por Putnam (1988), um Estado deve prover as necessidades dos seus nacionais, buscando inclusive soluções no cenário internacional quando sua capacidade nacional não o permitir, no chamado jogo de dois níveis. Entretanto, em um debate utilitarista, o que parecer ser uma necessidade na visão de um Estado não o seria na visão de outro ator estatal.

Assim sendo, como definir o que é uma necessidade de seus nacionais e como responder a elas? Atualmente, responder aos anseios de uma população nos espaços geográficos é algo complexo, que demanda energia e preparo. Realizar tais ações no espaço cibernético tende a ser um desafio maior, haja vista o pouco controle de que os Estados atualmente dispõem nesse ambiente.

Entra-se, dessa forma, no debate sobre a regulamentação do espaço cibernético. Este apresenta dois extremos: liberalizar ou restringir, que não podem ser vinculados a nenhuma categoria de atores. Isso porque no cenário internacional encontra-se atores estatais e não-estatais dos dois lados do debate. Ainda assim, pode-se afirmar que geralmente os atores não-estatais se posicionam em favor da liberalização, especialmente indivíduos, enquanto atores do setor privado, que visam lucro, e Estados, que visam controle, se posicionam em favor do uso restrito e controlado no espaço cibernético.

Dessa forma, sendo a atual Geopolítica vinculada principalmente à distribuição de poder dos Estados no cenário internacional, não se pode ignorar a relevância que os atores estatais ainda têm. Ademais, com a complexidade do mundo, o aumento do fluxo de informação e a aproximação das dinâmicas sociais do mundo, o poder está vinculado a controle. Assim sendo, pode-se concluir que estudar a geopolítica do espaço cibernético é debruçar-se sobre o controle dos Estados nesse novo espaço geográfico.

\section{GEOPOLÍTICA DO ESPAÇO CIBERNÉTICO E O FATOR DE CONTROLE}

A evolução da Geopolítica demonstra que as teorias criadas buscam responder a uma demanda do Estado, seja o poder ou a compreensão do equilíbrio de poder. Ser proposta por acadêmicos, mas servir a uma necessidade do Estado gera indecisão quanto à teoria, se ela é para a ciência ou 
para a política, acadêmicos ou atores estatais. Mesmo quando elaborada apenas para fins acadêmicos, uma teoria tem chance de se tornar uma política, conforme afirmado por Amado Cervo (2008).

Esse autor explica que a política externa de um país é resultado de sua percepção. A partir do momento em que os decisores e governantes adotam uma dada teoria como uma real perspectiva do mundo, ela pode se converter em uma política externa. Conforme seu trabalho, uma teoria tem etapas de maturação, como uma pessoa, sendo a transformação em política externa o alcance final da maturidade. Cervo (2008) cita por exemplo a teoria de Huntington, "O Choque de Civilizações", como inspiradora na Guerra do Afeganistão e do Iraque, e a "Teoria da Estabilidade Hegemônica”, que sugeriu o unilateralismo americano.

A apropriação de uma teoria para se fazer política já era vislumbrada pelas teorias clássicas da Geopolítica. A Teoria do Desafio e das Repostas de Arnold Toynbee, datada de 1934, afirmava que o Estado era comandado por elites dirigentes que utilizavam a Geopolítica como norteadora e indicadora de soluções, ou seja, utilizava essa ciência como uma ferramenta política (Bonfim 2005). Já no final do século XX, Robert Sack (1986) afirmava que a territorialização não deveria ser abordada como um conceito, mas como uma ferramenta política, pois poderia ser utilizada para controlar pessoas e coisas dentro de uma área, ou seja, uma estratégica geográfica poderosa.

A pesquisa de Sack (1986) pode ser aplicada a vários momentos históricos, pois questões complexas de territorialidade e fronteiras eram resolvidas pelos Estados com a instalações de muros, como a Muralha da China e o Muro de Berlim. Mas como solucionar questões relativas a poder no espaço cibernético? Os Estados sentem a necessidade de resguardar sua soberania no espaço cibernético, controlando possíveis ameaças cibernéticas, obtendo informações estratégicas e impedindo que informações comprometedoras sejam obtidas por outros atores, estatais ou não.

A sensibilidade do espaço cibernético e consequentemente a necessidade de controle surgem da transversalidade desse ambiente. Conforme explica Daniel Ventre (2012), o espaço cibernético tem pontos de conexão com os demais espaços geográficos, possibilitando impactar em todos eles e igualmente sofrer influências em cada um dos ambientes (Figura 1). 


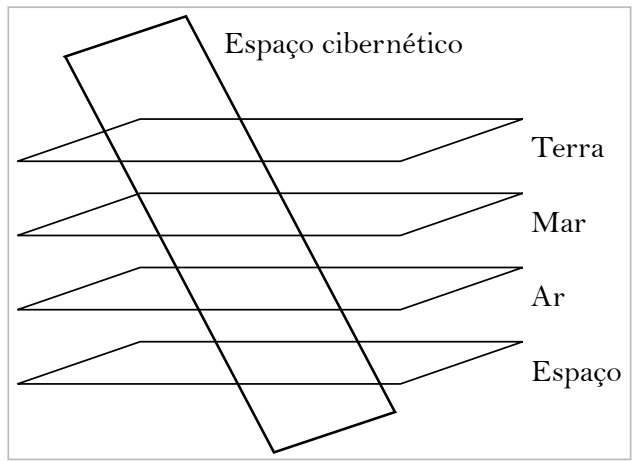

Figura 1 - Relação do Espaço Cibernético com os demais espaços geográficos.

Fonte: Ventre (2012, p. 35).

Por transpassar todos os demais espaços, o espaço cibernético é tido como uma potente ferramenta de controle pelo Estado, pois pode aplicar seu poder em todos os âmbitos. Diferente de um espaço tradicional, como o terrestre, em que o Estado está interessado em seu espaço total para a extração de recursos, no espaço cibernético há o interesse apenas na informação, que surge dentro dele mesmo e por meio das conexões. Dessa forma, a geopolítica do espaço cibernético não deve se preocupar em projetar um território cibernético semelhante aos demais espaços, mas apenas observar seus limites e fronteiras para com outros Estados e seus pontos de conexão com a terra, mar, ar e espaço. Cabe ressaltar, entretanto, que assim como uma ponte pode ser cruzada pelos dois lados, as conexões do espaço cibernético também são pontos frágeis para os Estados, que devem defendê-los e controlá-los.

Dito isso, recorda-se que o espaço cibernético surge de uma criação dos Estados Unidos, sediando as principais empresas detentoras do domínio e abrangência desse ambiente. Assim, há um controle público por organizações governamentais - Internet Corporation for Assigned Names and Numbers, Internet Society, World Wide Web Consortium - e por empresas, sendo as principais americanas, como, a Google e a Microsoft (Portela 2015). Essa posição privilegiada no cenário internacional incomoda outros autores internacionais.

Dessa forma, no espaço cibernético, a multiplicidade de poder no cenário internacional causa o surgimento de movimentos entre os Estados, e uma concordância praticamente consensual entre todas as novas teorias da Geopolítica, reservadas as diferenças entre elas e algumas exceções. $\mathrm{Na}$ 
visão de Lucas Soares Portela (2015), as relações internacionais no espaço cibernético podem ser pautadas pelo o que pode ser chamado de "Teoria dos Movimentos Centrais e Subjacentes". De acordo com ele, existem dois tipos de movimentos maiores nas relações internacionais, que são criados por meio de articulações de atores estatais e não-estatais:

Quadro 1

Movimentos Centrais e Subjacentes do Espaço Cibernético

\begin{tabular}{|l|l|l|l|}
\hline \multicolumn{1}{|c|}{ Categoria } & \multicolumn{1}{|c|}{ Movimento } & \multicolumn{1}{c|}{ Exemplos } & \multicolumn{1}{c|}{ Atores } \\
\hline \multirow{2}{*}{ Centrais } & \multirow{2}{*}{ Centrais } & Five Eye Group (Echelon) & Estatais \\
\cline { 3 - 4 } & & Safe Harbor & Mistos \\
\hline \multirow{3}{*}{ Subjacentes } & \multirow{2}{*}{ Alternativos } & BRICS Cable & Estatais \\
\cline { 3 - 4 } & & Estônia, Irlanda e Microsoft & Mistos \\
\cline { 3 - 4 } & & Deep Web & Não estatais \\
\cline { 3 - 4 } & \multirow{2}{*}{ Reacionários } & Alemanha-Brasil & Estatais \\
\cline { 3 - 4 } & & Buracos Negros & Estatais \\
\hline
\end{tabular}

Fonte: Elaboração própria baseada em Portela (2015).

Conforme o autor, os "Movimentos Centrais" são aqueles conduzidos por Estados potenciais interessados em manter suas posições e o status quo do sistema internacional, ou seja, manter o controle das relações internacionais, podendo ou não ter participação de atores não-estatais. Os "Movimentos Alternativos" são compostos por Estados e/ou atores não estatais interessados na mudança dos principais atores estatais do sistema internacional, sem alterar a estrutura do sistema internacional. Por sua vez, os "Movimentos Reacionários" são aqueles em que os atores estatais e/ou não estatais estão interessados na mudança tanto dos principais atores internacionais e da estrutura internacional vigente.

Cabe ressaltar ainda que os movimentos são formados conforme as áreas e que um Estado pode compor vários movimentos (Portela 2015). Assim, o Brasil faz parte de um movimento alternativo, ao compor o movimento do BRICS Cable, mas também compõe um movimento reacionário com a Alemanha. No caso do movimento alternativo, o Brasil apenas pretende subir à posição de um dos principais atores internacionais no espaço cibernético, juntamente com Rússia, Îndia, China e África do Sul. Já no movimento reacionário com a Alemanha, o Brasil pretende se tornar um dos principais atores internacionais do espaço cibernético, como mudar a 
estrutura desse ambiente, especialmente a forma como é controlado pelos Estados centrais.

Dentro dos movimentos centrais existem grupos de controle e captação de informações no espaço cibernético. O principal deles é o movimento chamado de Five Eyes Group, que tem esse nome por ser composto por cinco Estados, a saber, Estados Unidos, Reino Unido, Austrália, Canadá e Nova Zelândia (Fabregat 2013). Esse grupo compõe uma rede chamada "Echelon", formada por 16 bases espalhadas pelo globo, que operam em cinco zonas de escuta que observam e analisam todas as informações que transitam no ambiente nas conexões aéreas do espaço cibernético, por isso o nome "cinco olhos".

Embora participe desse grupo, os Estados Unidos também têm outra rede de controle e observação do espaço cibernético, chamada de "Carnivore". Embora seu alcance não seja conhecido, sabe-se que essa rede instala um programa em todas as conexões, que verifica a legalidade ou ilegalidade de uma comunicação (Fabregat 2013). Enquanto a rede "Echelon" tem como base a Agência de Segurança Nacional dos Estados Unidos (NSA), a rede "Carnivore" é comandada pelo Federal Bureau of Investigation (FBI).

Cabe ressaltar que, como procede da mesma raiz da rede do Five Eyes Group, o alcance da "Carnivore" pode ser igual ou até mesmo maior que a "Echelon" (Fabregat 2013). Também desconhecida é a existência e alcance das redes da Rússia e da China. O que se sabe é que ambos os países apresentam poder e capacidade cibernética para atuação em qualquer parte do globo e tem cooperado nesse setor, o que não permite a eliminação da hipótese de uma rede de controle e observação.

No que diz respeito à Europa, existem dois movimentos menores, um da União Europeia como um todo e outro envolvendo França, Espanha e Itália. O primeiro movimento opera a rede Enfopol, que tem o objetivo de conter os crimes no continente e evitar o terrorismo, utilizando para isso a interceptação e o monitoramento de comunicações. Por sua vez, França, Espanha e Itália estão desenvolvendo uma rede de inteligência militar, chamada de Osemiti, que realiza analises semânticas baseadas em palavras ditas e escritas por telefonemas e e-mails.

Assim, o mundo sobre a ótica dos Movimentos Centrais se configura como mostra a Figura 2. 


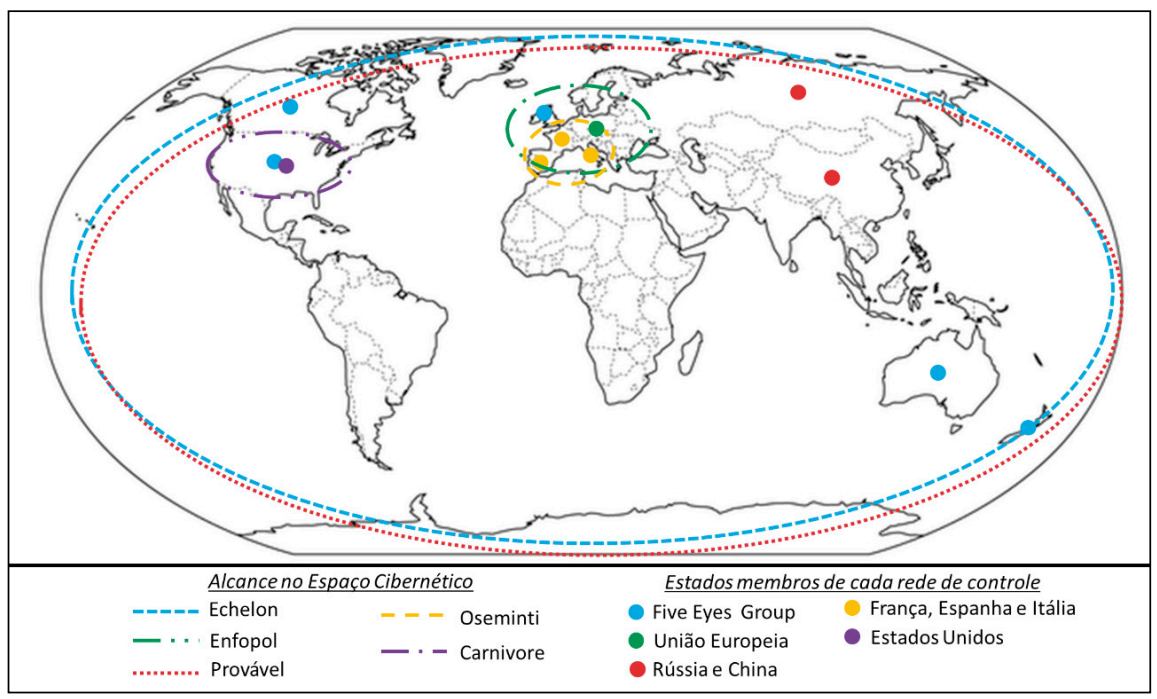

Figura 2 - Principais sistemas de controle e observação do espaço cibernético. Fonte: Elaboração própria baseada em Fabregat (2013).

Essas redes demonstram que atualmente os Estados estão preocupados em controlar e observar o espaço cibernético. Captar as informações que transitam nesse espaço permite a geração de conhecimento, que resulta em poder. Dessa forma, a geopolítica do espaço cibernético pauta-se nos fatores geradores de poderes, seguindo a tendência das novas teorias da Geopolítica.

As centralidades dos países relacionados acima também estão vinculadas com suas posições de potencias cibernéticos. São Estados com destaque em proporção de usuários por população, detentores de controladores da Internet, produtores de conhecimento, contexto socioeconômico, infraestrutura tecnológica e marcos regulatórios (Portela 2015). Embora os Estados Unidos apresentem destaque e distanciamento em todos esses quesitos, Fareed Zakaria (2008) advoga que a estabilidade desse país depende da convivência com os demais atores-estatais.

Afirma ainda que, por isso, o mundo deve se configurar em um sistema de centros e raios, em que todos os assuntos tratados pelos raios devem passar pelos centros. Assim, o controle e manutenção da relação entre Estados centrais e Estados raios (Portela, 2015) é realizada pelas redes demonstradas na figura anterior. Finalmente, o espaço cibernético permite o exercício da soberania por meio do controle. 


\section{CONSIDERAÇÕES FINAIS}

As teorias da Geopolítica evoluíram conforme a necessidade dos Estados. Por servir ao interesse de desenvolvimento, sobrevivência e exercício da soberania, as teorias buscavam meios de beneficiar os atores estatais. Com o final da Guerra Fria, o fator relacional que pautava as teorias passou da necessidade de beneficiar os Estados para a necessidade de se compreender o mundo. Tal mudança, entretanto, não desinteressa as teorias ao Estado, pois ao compreender o mundo também se compreende como usufruir de seus recursos.

A informação assim se torna primordial para um país, sendo a principal fonte o espaço cibernético. Esse ambiente, embora não tenha um território tangível como os demais espaços geográficos, pode assim ser caracterizado por conter relações sociais e posicionamentos de poder por parte dos Estados. Consequentemente também pode ter aplicado a ele teorias Geopolíticas, haja vista que as novas teorias estão preocupadas com o equilíbrio de poder para explicar o mundo.

A incerteza em lidar com o espaço cibernético e a necessidade de se obter informações relevantes à sua soberania instigam os Estados a obterem controle desse ambiente - ainda mais interessados ao saberem que podem ser ameaçados por outros atores estatais e também não-estatais por meio desse ambiente. Assim, buscam projetar seu poder nesse ambiente por meio do controle cibernético. Conclui-se, assim, que estudar a geopolítica do espaço cibernético é debruçar-se sobre o controle dos Estados nesse novo espaço geográfico.

O controle do Estado nesse ambiente dá-se não apenas dentro do próprio espaço cibernético como nos demais espaço geográficos. Isso porque o espaço cibernético transpassa todos os demais, coletando informações e monitorando-os. Uma ação no espaço cibernético pode causar impactos nos demais, sendo a recíproca verdadeira. Assim o alcance dos olhos do Estado e a possibilidade de projeção de poder são elevados.

As dinâmicas do poder no espaço cibernético assemelham-se àquelas observadas no sistema internacional tradicional. Embora controle uma parte significativa de empresas e provedores de Internet, os Estados Unidos não são mais um controlador universal, como era ainda na Guerra Fria. A complexidade do espaço cibernético também o torna multipolar, assim como o todo do sistema internacional.

A necessidade de garantir a sobrevivência e desenvolvimento nesse cenário instiga os Estados a se movimentarem, seja bilateralmente ou multilateralmente, nos chamados Movimentos Centrais e Subjacentes. Os movimentos centrais congregam potencias em posição de destaque no ce- 
nário internacional que articulam para a manutenção de suas posições e da estrutura internacional vigente. No âmbito do espaço cibernético, esses atores estatais perseguem esses objetivos por meio de redes de controle e observação, a saber:

- Echelon: Five Eyes Group, liderados por Estados Unidos (NSA) e Reino Unido;

- Enfopol: União Europeia;

- Oseminti: França, Espanha e Itália;

- Carnivore: Estados Unidos (FBI);

- Rússia e China.

Tais redes permitem o monitoramento das relações com os Estados raios e garantindo o exercício da soberania, seja no próprio espaço cibernético ou seja com a projeção de poder nos demais espaços geográficos. As disputas de poder observadas nesse cenário condizem com a necessidade de se explicar, por parte das novas teorias da Geopolítica, o equilíbrio de poder e a necessidade de controle dos principais atores internacionais. Dessa forma, conclui-se que o espaço cibernético pode ser objeto de pesquisa da geopolítica a partir da análise da aplicação contemporânea do conceito de poder, desde que esse seja trabalhado dentro das atipicidades apresentadas pela geopolítica do espaço cibernético.

\section{REFERÊNCIAS}

Aron, Raymond. 1979. Paz e Guerra entre as Nações. Brasília: Editora Universidade de Brasília.

Bonfim, Uraci Castro. 2005. Geopolítica. Curso de Política, Estratégia e Alta Administração do Exército. Ensino a Distância CPAEX/EAD. Rio de Janeiro: ECEME.

Burns, Edward Macnall. 1948. História da Civilização Ocidental. v. 1. Rio de Janeiro: Ed. Globo.

Castro, Therezinha. 1999. Geopolítica: princípios, meios e fins. Rio de Janeiro: BIBLIEx.

Cervo, Amado. 2008. Inserção Internacional: formação dos conceitos brasileiros. São Paulo: Ed. Saraiva.

Clarke, Richard A. 2010. Cyber War: the next threat to national security and what to do about it. New York: HarperCollins Publishers. 
Costa, Wanderley Messias da. 1992. Geografia Política e Geopolítica: Discursos sobre o Território e o Poder. São Paulo: HUCITEC e Editora da USP.

Fabregat, Clemente Herrero. 2013. El resurgimiento de la geopolítica: la Geopolítica Cibernética. Revista de Geopolítica, 4 (1): 15-35, jan./jun. Rio Grande do Norte: UFRN.

Ferreira Neto, Walfredo B. 2014. Territorializando o "novo" e (re)territorializando os tradicionais: a cibernética como espaço e recurso do poder. In: Medeiros Filho, Oscar; Ferreira Neto, Walfredo B.; Gonzales, Selma Lúcia de Moura (Org.) Segurança e Defesa Cibernética: da fronteira física aos muros virtuais. Coleção I Defesa e Fronteiras Cibernéticas. Pernambuco: Editora UFPE.

Gonzales, Selma Lúcia de Moura e Lucas Soares Portela. 2017. A geopolítica do espaço cibernético Sul-americano: conformação de políticas de segurança e defesa cibernética. Anais do $6^{\circ}$ Encontro da Associação Brasileira de Relações Internacionais - ABRI. Belo Horizonte: ABRI.

Huntington, Samuel. 1997. O Choque das Civilizações e a recomposição da Nova Ordem Mundial. Rio de Janeiro: Objetiva.

Losano, Mario G. 2008. Karl Haushofer (1869-1946): o pai da geopolítica das ditaduras europeias.

Nye Jr, Joseph S. 2012. O futuro do poder. São Paulo: Benvirá.

Portela, Lucas Soares. 2015. Movimentos centrais e subjacentes no espaço cibernético do século XXI. Dissertação de Mestrado [Ciências Militares]. Rio de Janeiro: ECEME.

Putnam, Robert D. 1988. Diplomacy and Domestic Politics: The Logic of Two-Level Games. International Organization, 42 (3). Massachusetts: MIT Press.

Raffestin, Claude. 1993. Por uma Geografia do Poder. Paris: Ed. Ática.

Ratzel, Friedrich. 2011. A relação entre o solo e o Estado - Capítulo I: O Estado como organismo ligado ao solo [p. 59]. Tradução de Matheus Pfrimer. Revista Espaço e Tempo, 29: 51-58. São Paulo: GEOUSP.

Sack, Robert. 1986. Human Territoriality: its theory and history. Cambridge: Cambridge University Press.

Santos, Milton. 1986. Por uma Geografia Nova. 3. ed. São Paulo: Ed. Hucitec. 
Singer, Peter. 2004. Um Só Mundo: A Ética da Globalização. São Paulo: Martins Fontes.

Ventre, Daniel. 2012. Ciberguerra. In: Academia General Militar. Seguridad global y potências emergentes em um mundo multipolar. XIX Curso Internacional de Defensa. Espanha: Universidad Zaragoza.

Villa, Rafael Duarte. 2000. Mackinder: Repensando a Política Internacional Contemporânea. Revista de Sociologia e Política, 14: 195-199, jun. Paraná: UFPR.

Violante, Alexandre Rocha. 2015. A Teoria do Poder Marítimo de Mahan: uma análise crítica à luz de autores contemporâneos. Revista da Escola Guerra Naval, 21 (1): 223-260, jan./jun. Rio de Janeiro: EGN.

Zakaria, Fareed. 2008. O mundo pós-americano. São Paulo: Companhia das Letras. 


\section{NOTAS}

1. Poder Inteligente é um conceito criado por Joseph Nye Jr (2012) e diz respeito à mescla do poder duro e brando, ou seja, o uso da força com base nos recursos informacionais e das ferramentas, métodos e influência do Estado.

2. Advanced Research Projects Agency Network (ArpaNET) foi o primeiro protótipo da Internet criado em 1969, por meio de trabalhos acadêmicos no âmbito da RAND Corporation. Inicialmente a ArpaNET era composta por quatro computadores localizados em universidades estadunidenses.

3. Walfredo Ferreira Neto afirma que no espaço cibernético a um processo de territorialização do novo e de reterritorialização do que já existe, ou seja, não há uma desterritorialização nesse ambiente. Assim não há um espaço raffestiniano dentro do espaço cibernético. 


\section{GEOPOLÍTICA DO ESPAÇO CIBERNÉTICO E O PODER: \\ O EXÉRCICIO DA SOBERANIA POR MEIO DO CONTROLE}

\section{RESUMO}

O surgimento do chamado espaço cibernético deu-se no meio acadêmico, no imaginário do homem. Surgiu para responder a uma demanda humana, sendo utilizado desde sua origem. A relevância que esse espaço tomou na vida da sociedade e do homem já é objeto de desavenças entre homens e litígios entre Estados.

Atualmente, muito se tem falado sobre a equiparação do espaço cibernético a um espaço geográfico, delimitações de fronteiras, soberania de Estado, controle governamental e disputa de poderes. Acredita-se também que a importância do espaço cibernético para o Estado tem uma relação direta com seu poder e soberania, conceitos que estão interligados ao espaço, universos estes que são estudados pela Geopolítica.

Assim, esse artigo pretendeu responder ao problema: a dinâmica do poder do século XXI gera uma territorialização do espaço cibernético como um espaço geográfico? A hipótese que norteou o artigo afirma que a projeção de poder, visando o controle, dentro do espaço cibernético, seja por Estados ou outros atores, desenha uma relação que se enquadra dentro da chamada nova geopolítica. $\mathrm{O}$ artigo foi estruturado em quatro tópicos temáticos sobre evolução da geopolítica, categorias constitutivas do território, nova geopolítica e relação com o poder e a geopolítica do espaço cibernético e o fator de controle.

Ao final do artigo, conclui-se que o espaço cibernético pode ser objeto de pesquisa da geopolítica a partir da análise da aplicação contemporânea do conceito de poder, desde que esse seja trabalhado dentro das atipicidades apresentadas pela geopolítica do espaço cibernético.

Palavras-chaves: Geopolítica; Espaço cibernético; Poder; Controle; Espaço geográfico.

\section{ABSTRACT}

The emergence of the so-called cybernetic space occurred in the academic environment, in the imaginary of man. It arose to respond to a human demand, being used since its origin. The relevance that this space has taken in the life of society and man is already the subject of disagreements between men and disputes between States. 
At present, much has been said about the equation of cyber space to a geographical space, boundary delimitations, state sovereignty, government control and power disputes. It is also believed that the importance of the cybernetic space for the State has a direct relation with its power and sovereignty, concepts that are interconnected to the space, universes that are studied by Geopolitics.

Thus, this article sought to answer the problem: the power dynamics of the 21 st century generates a territorialization of cyber space as a geographic space? The hypothesis that guided the article states that the projection of power, aiming at control within the cyber space, whether by states or other actors, draws a relationship that falls within the so-called new geopolitics. The article was structured in four thematic topics on geopolitical evolution, territorial constituent categories, new geopolitics and relation with the power and geopolitics of cyber space and the control factor.

At the end of the article, it is concluded that the cybernetic space can be object of geopolitics research from the analysis of the contemporary application of the concept of power, provided that it is worked within the atipicities presented by the geopolitics of the cybernetic space.

Keywords: Geopolitics; Cyber Space; Power; Control; Geographic Space. 